\title{
Programa PET-Saúde: trajetória 2009-2010, na Universidade de Brasília
}

\author{
PET-Health Program: 2009-2010 course at the University of Brasilia
}

Remulo Orlando Borges da Silva', Elioenai Dornelles Alves², Dandara Sampaio Leão de Carvalho³, Diego Martins Mesquita ${ }^{4}$

1 Graduando em Medicina pela Universidade de Brasília (UnB) - Brasília (DF), Brasil. remuloorlando@gmail.com

${ }^{2}$ Livre Docente pela Universidade Federal do Rio de Janeiro (UFRJ) - Rio de Janeiro (RJ), Brasil. Professor titular do Programa de Pósgraduação de Enfermagem da UnB - Brasília (DF), Brasil.

elioenai@unb.br

${ }^{3}$ Graduanda em Medicina pela UnB - Brasília (DF), Brasil.

darinhasampaio@hotmail.com

${ }^{4}$ Graduando em Medicina pela UnB - Brasília (DF), Brasil.

diego_martins_mesquita@yahoo.com.br
RESUMO Este estudo consiste em um relato de experiência derivada do PET-Saúde, implantado na UnB e inserido na realidade da comunidade do Paranoá-DF, durante o período 2009-2010. Entre as atividades desenvolvidas, estão: a elaboração de instrumento de dados estruturado em moldes da Medicina da Família; a criação de um portfólio eletrônico; a realização de oficinas de capacitação; entre outras. Dos resultados obtidos, foi possível verificar uma mudança na postura acadêmica, formando futuros profissionais mais críticos, reflexivos, empáticos e preocupados efetivamente com a Atenção Primária à Saúde.

PALAVRAS CHAVE: Atenção Primária à Saúde; Visita Domiciliar; Equipe de Assistência ao Paciente; Saúde da Família.

ABSTRACT This study is composed of a report of experience derived from PET-Health, established in UNB and inserted into the reality of community Paranoá-DF, during the period 20092010. Among the activities are: development of an instrument of data structured in a manner of Family Medicine; the creation of an electronic portfolio, the holding of training workshops, among others. From the acquired results, it was observed a change in academic attitude, making future professionals more critical, thoughtful, empathetic and really concerned with the Primary Health Care.

KEYWORDS: Primary Health Care; Home Visit; Patient Care Team; Family Health. 


\section{Introdução}

O Sistema Único de Saúde (SUS) visa à integralidade, à universalidade e à equidade. Entretanto, apesar dos avanços já obtidos na consolidação desse sistema e de seus princípios basilares, no SUS, ainda há uma significativa fragmentação dos profissionais e de suas relaçôes.

A formação na graduação de um profissional de saúde crítico, reflexivo, preparado para atuar em equipe e no mercado de trabalho, exige uma série de experiências de ensino-aprendizagem diferenciadas. Os cenários de trabalho no SUS e no mercado estão mudando, e a Atenção Primária à Saúde (APS) passou a ser um cenário essencial para ajudar na formação desse novo profissional (ALVES, 2005). Os Ministérios da Saúde e da Educaçáo brasileiros, entendendo isso como uma necessidade para a adequada implantação do SUS, têm promovido várias iniciativas para estimular a aproximação das Universidades dos serviços de saúde não hospitalares, como o Pro-med, o Pro-saúde, o PET-Saúde, entre outros (PINTO et al, 2009).

A Universidade está cada vez mais voltada para desenvolver atividades de extensão, com o objetivo de que façam parte da proposta pedagógica dos cursos, principalmente na área da saúde. A finalidade é que o aluno transponha os muros da instituição, amplie e enriqueça a sua visão sobre a realidade sociopolítica local. Dessa forma, o aluno já inicia sua interação com a sociedade e amadurece os pensamentos científico e social sobre o seu futuro exercício profissional, dentro de um processo educativo que prioriza e enfatiza a importância da prestação de serviços à comunidade (PEREIRA et al, 2007; PINTO et al, 2009).

Em 2008, os Ministérios da Saúde e da Educação instauraram o Programa de Educaçáo pelo Trabalho para a Saúde, o PET-Saúde, com os objetivos de: fomentar a formação profissional articulada à Estratégia de Saúde da Família; facilitar o processo de integração entre o ensino, os serviços e a comunidade; e estimular a inserção das necessidades dos serviços na produção de conhecimento nos Cursos de Graduação. O Programa é desenvolvido por estudantes que realizam atividades nos serviços de saúde de forma sistemática, com preceptores (trabalhadores dos serviços) e com tutores
(professores).Os alunos, oriundos de vários Cursos de Graduação da área da Saúde, são organizados em grupos multidisciplinares. Atividades assistenciais, de capacitação e de pesquisa são realizadas conjuntamente nos serviços, promovendo a aprendizagem significativa por meio da integração, das trocas contínuas e da construção conjunta (REGINA, 2010; BRASIL, 2007).

A Universidade de Brasília (UnB), a partir do PET-Saúde, insere-se em um novo objetivo pedagógico, articulando uma tríade de pesquisa, ensino e extensão. $\mathrm{O}$ programa dos Ministérios estimula o estudante a produzir pensamentos próprios, valorizando um pensar científico e social, na medida em que há uma inserção na participação ativa para discutir e avaliar os problemas locais, estabelecendo um foco na atenção primária à saúde (BRASIL, 2008).

No PET-Saúde da UnB, grandes grupos Tutoriais de trabalho multiprofissionais são formados para atuação em comunidades locais. É objetivo deste relato a descrição das atividades desempenhadas pelos grupos tutoriais na comunidade do Paranoá-DF, cidade de aproximadamente cem mil habitantes, localizada a 20 km de Brasília.

Cada grupo Tutorial preestabelecido é constituído por alunos, monitores, preceptores e tutores, compondo uma equipe em que cada parte contribui para o processo de ensino-aprendizagem, a partir dos problemas clínicos da comunidade e de um plano de ação específico.

Quanto às disposiçóes gerais e organizacionais dos integrantes do PET-Saúde, na Universidade de Brasília, existe a seguinte divisão: Coordenador PET, Tutores, Preceptores, Bolsistas e Alunos. Os Tutores são professores vinculados à universidade, cada um responsável pela organização das áreas temáticas respectivas de cada curso da saúde: medicina, odontologia, enfermagem, farmácia, nutrição e saúde coletiva. Os preceptores são funcionários da Secretária de Saúde do Distrito Federal, todos atuantes na atenção primária, sendo que cada profissional deverá exercer carga horária semanal de 8 horas, acompanhando bolsistas e alunos nas atividades práticas na comunidade. Os Bolsistas PET são acadêmicos dos cursos da saúde, selecionados a partir de edital interno prévio. Todos recebem bolsa mensal durante o 
prazo correspondente à duração do edital. O programa também recebe estudantes não-renumerados e alunos regulares de disciplinas, os quais utilizam a estratégia PET para execução do plano pedagógico, vivenciando a realidade local e a prática profissional individualmente ou em equipe.

Este artigo se classifica como um Relato de experiência baseado nas práticas integradoras do PET-Saúde, correspondente aos anos de 2009 e 2010, na Universidade de Brasília. O foco principal é descrever como se desenvolveu o programa, apresentando uma visão integrada de tutores e alunos que participaram da implantação e do funcionamento do programa, expondo uma reflexão crítica das rotinas, resultados e políticas criadas e implementadas na comunidade.

Quanto aos aspectos éticos, não há restriçôes, pois não foi utilizado na composição deste artigo nenhum tipo de questionário ou de experiência interpessoal com seres humanos. Para a construção deste relato, foram elaboradas as seguintes etapas: 1) revisão bibliográfica nos bancos de dados SciELO, LILACS, BIREME, BVS, MEDLINE, no período de 2000 a 2010, com os seguintes unitermos: PET-saúde, medicina da família e atenção primária em saúde; 2) destacado dos estudos validados na realidade brasileira em comparação com outros programas semelhantes, de outras instituiçóes; 3) a equipe envolvida: estudantes bolsistas, preceptores e coordenadores se reuniram em diversas ocasióes para registro de suas experiências, limitaçóes e críticas; 4) Análise crítica das experiências; e 5) Reflexão teórica da literatura.

\section{Relato de Experiência}

Dentro da tríade proposta pelo PET-Saúde, extensãoensino-pesquisa, as atividades desenvolvidas estão intimamente inseridas na realidade do Paranoá-DF, atuando em uma esfera multidisciplinar, visando à melhoria da Atençáo Básica e da formação de profissionais atualizados, na perspectiva de mudança do processo de trabalho em saúde (ALVES, 2005).

As atividades práticas, realizadas com a supervisão de preceptores locais e de monitores, elegem uma situação encontrada na comunidade e, com a aplicação da metodologia da problematização, realizam uma ação de forma interdisciplinar nas comunidades. Como exemplo de atividades realizadas, podemos citar: a criação de portfólio eletrônico Moodle-Aprender, visitas domiciliares, construção de um modelo de prontuário PET (estruturado em moldes da medicina familiar), oficinas de capacitação, feiras de saúde, organização de grupos educativos, discussão de casos clínicos, entre outras.

O ensino prático, envolvendo estudantes da Universidade, está associado à atuação das equipes multidisciplinares que realizam visitas semanais nas residências da comunidade do Paranoá, cadastradas no Posto de Saúde da Quadra 18. As visitas domiciliares apresentam um caráter investigativo da realidade individual de cada componente da família, bem como a promoção de uma consciência de autocuidado familiar e a orientação de perspectivas auxiliadoras na melhoria da qualidade de vida.

As visitas domiciliares (VD) norteiam um caráter essencial da formação de um novo profissional da Saúde, centrado no conhecimento da história da Comunidade, no diagnóstico inserido na realidade biopsicossocial do indivíduo, além do conhecimento da realidade de cada profissional da Saúde, em seu contexto de atuação dentro da equipe de Atenção Primária em Saúde, e de sua importância no contexto global de promoção de saúde. Outro fator importante é o incentivo na formação técnica, cognitivo-motora e afetiva da relação profissionalpaciente dos acadêmicos.

Para que isso pudesse ser alcançado, foram programadas atividades de capacitação com preceptores e tutores, de maneira a homogeneizar a linguagem de todos. Além desses momentos com o grande grupo, a dinâmica de trabalho envolve encontros frequentes entre o tutor e seus preceptores para avaliar e programar as visitas (PINTO et al, 2009). Como os contextos domiciliares são trabalhados por meio do reconhecimento das diferenças, existiu uma demanda para elaboração e sistematização de um modelo de coleta de dados que atendesse, de modo integral, às necessidades da saúde das famílias dessa comunidade, abordando as principais estratégias do SUS e do Programa Saúde da Família. 
A construção desse modelo de coleta de dados culminou na criação do Prontuário PET. A organização do Prontuário PET obedece a uma sequência já conhecida e bastante utilizada na identificação de demandas e necessidades dos usuários: conhecimento, percepção e definição dos problemas e demandas do doente; definição dos objetivos terapêuticos e das açóes e tarefas que serão negociadas com o paciente; divisão de responsabilidades entre a equipe; avaliação das açóes e novas condutas.

O Prontuário PET estimula e fortalece o trabalho em equipe e o diálogo entre os profissionais e alunos, favorecendo troca de conhecimentos, inclusive com os doentes e familiares, gerando essa noção de dimensão global da saúde do paciente. Contribui também para a produção de vínculos e para o fortalecimento do sentido de grupo, que visa a sustentar as construçóes que foram elaboradas coletivamente, além de estimular o empenho no trabalho.

Outro ponto importante na utilização desse Prontuário são os benefícios gerados para as famílias cadastradas, em termos de qualidade e uniformidade do serviço. A qualidade do atendimento prestado, o afeto, o vínculo e a conduta dos casos são intimamente influenciados pelo cuidado e pelas orientaçóes proscritas pelo instrumento de coleta de dados. Desse modo, há notável ganho na qualidade de vida das famílias atendidas pelo PET-saúde. Dos pontos abordados do prontuário, em especial, aqueles que trazem maior benefício para a qualidade de vida e para a observação clínica da família são as Listas de Problemas Familiares e a Folha de Evolução da Visita Domiciliar.

Após a realização das Visitas Domiciliares, como rotina pré-definida, existe um debate na sala de reunióes do Posto de Saúde, no qual discutimos e aprimoramos as condutas dos casos clínicos que estão sendo acompanhados, bem como realizamos o levantamento das necessidades. Essa atividade enriquece o conhecimento de todos e estabelece uma cobrança do comprometimento com as atividades dos integrantes. A partir dela, os casos são aprofundados, os diagnósticos são solucionados e é fortalecida a estratégia do plano de cuidado da família, constituindo as bases do futuro profissional da saúde.

Dessa forma, a atividade de Visita Domiciliar une os esforços da academia e do serviço da Regional de Saúde do Paranoá. Esse laço entre diferentes meios de trabalho fortalece a estratégia de Saúde da Família e produz diversos resultados teóricos e práticos, tanto na reorientação curricular dos cursos da saúde na Universidade quanto na modificação da rotina de trabalho dos Profissionais da Saúde. Esse mesmo laço constrói com as famílias atendidas pelo programa uma relação de parceria e empatia, fundamental no direcionamento de soluçóes para as múltiplas problemáticas de cada família (AGUIAR et al, 2010).

Outro pilar preconizado pelo PET-Saúde é a extensão, caracterizada pela construção de oficinas de capacitação dos Alunos de Graduação, objetivando o conhecimento das áreas de Atenção Primária e de Saúde da Família. Diversos temas comumente abordados visam à apresentação e reorientação de perspectivas do serviço de saúde local, bem como à construção de novas expectativas. Existe também a necessidade de uma pactuação de novas programações, mediante um cronograma de atividades anuais que estabelece diretrizes e parâmetros.

Comumente, através das oficinas, também são apresentadas as linhas de pesquisa em atuação na Regional do Paranoá, promovendo estímulo à entrada de novos acadêmicos, apoio de docentes e do corpo de saúde do Paranoá. Outras oficinas desenvolvidas objetivam atingir a comunidade em algum aspecto, motivando uma reavaliação postural e uma conscientização de temas prevalentes no cotidiano da Comunidade.

Dentre os resultados já obtidos com o programa, podemos citar também a criação e a construção do portfólio eletrônico: o Moodle-Aprender. Nesse portfólio, todos os petianos podem registrar suas contribuiçóes com as práticas para que sejam disponibilizadas a todos. Dentre os registros, podemos citar a evolução das Visitas Domiciliares, os livros-textos, artigos científicos, notícias organizacionais e descrição de projetos científicos.

Outro caráter essencial, desenvolvido durante as atividades do PET-Saúde, foi o desenvolvimento de grandes projetos científicos na comunidade. Essas pesquisas têm a finalidade de reconhecer, avaliar e qualificar os serviços do PSF, beneficiando a comunidade e desenvolvendo o caráter crítico dos alunos diante das realidades vividas. 
Dentro desse quadro de atividades exercidas pelo PET, diversos fatores facilitadores e dificultadores surgiram, acompanhando o desenvolvimento e a implantação do programa.

A facilidade de implantação no Paranoá foi propiciada por esforços conjuntos de professores e alunos, e do apoio incondicional dos Conselheiros Regionais de Saúde do Paranoá, possibilitando, entre outros, a existência de um espaço físico para a realização das contínuas atividades na Comunidade. Entre os aspectos positivos, podemos citar também a facilidade de acesso aos profissionais do serviço, que cumprem horários regulares e permitem uma maior organização e integração dos diversos projetos dentro do Programa. Assim, o serviço pode ser realizado de maneira eficaz, contribuindo para a satisfação da comunidade atendida e dos próprios estudantes em fazer parte de um trabalho inovador na Universidade. Essa integração com o serviço permite o desenvolvimento de uma relação de trabalho democrática, ética e transparente, propiciando o sucesso das atividades e a consequente melhoria da qualidade de vida da comunidade.

A mudança da mentalidade dos acadêmicos também foi um efeito facilitador, na medida em que novas exigências surgiram, evidenciadas pela criação e pelo fortalecimento da Liga Acadêmica de Saúde da Família, pela contratação de um professor titular com especialização em Medicina da Família e Comunidade, e pelo pleito, com os organismos políticos internos da faculdade (Centro Acadêmico e Conselho Acadêmico), pela reorganização das disciplinas clínicas com maior enfoque na Medicina de Família.

Entretanto, é necessário ressaltar os fatores dificultadores para a contínua reavaliação e melhoria do Programa. Por parte da Secretaria de Saúde do Distrito Federal, falta uma ampliaçáo das equipes do PSF na Regional de Saúde do Paranoá, para uma multiplicação das experiências positivas ocorridas. A resistência por parte dos Agentes Comunitários de Saúde, que, devido ao insucesso no pleito de bolsas de pesquisa, não interagem completamente com os acadêmicos durante as atividades, enfraquecendo uma visão mais ampliada da integraçáo dos múltiplos profissionais da área da Saúde.
Outros fatores dificultadores, como os constantes eventos burocráticos e a ausência de um secretariado dentro da Regional de Saúde para assuntos específicos do PET, atrasam o desenvolvimento de atividades. A não fixação de equipe de gestores locais gera uma necessidade de frequentes repactuaçóes, havendo, muitas vezes, falta de investimentos da Secretaria de Saúde em equipamentos básicos para a realização das atividades.

As dificuldades também estão presentes dentro da própria Universidade, por intermédio de um baixo apoio da direção. Evidenciamos alguns problemas técnico-administrativos envolvendo o transporte para os locais de atividade, e constantes períodos de greve da Universidade.

\section{Conclusão}

A formação de um profissional de saúde crítico, reflexivo, preparado para atuar em equipe e no mercado de trabalho exige uma série de experiências de ensinoaprendizagem diferenciadas (PEREIRA et al, 2008).

Os resultados obtidos nas avaliaçóes e no acompanhamento dos alunos sugerem que os objetivos de inseri-los em equipes multiprofissionais, capacitá-los para problematizar a realidade e planejar açóes de modificação de situaçóes de risco em equipes multiprofissionais foram alcançados. Os próprios acadêmicos consideraram que a participação no programa foi importante para a sua formação (PINTO et al, 2009).

É necessário, no entanto, aprofundar a investigação de como essa experiência poderá influenciar na formação final desse profissional de saúde, e se ele estará mais apto para integrar as equipes multiprofissionais propostas pelo SUS.

Apesar dos diversos aspectos dificultadores relatados, o aprendizado pela prática, o contato com a comunidade carente, a convivência com os profissionais do serviço da Estratégia Saúde da Família, possibilitados pelo PET-Saúde, interferem na mudança do foco dos futuros profissionais da saúde, sendo atingido com sucesso um dos principais objetivos da implementação do Projeto no Brasil. 
Os alunos mobilizados interagem com o restante da comunidade discente, propondo mudanças curriculares no âmbito da atenção primária.

Percebe-se a necessidade de uma extrapolação dessa experiência para outras localidades, possibilitando uma ampliaçáo dos efeitos positivos propiciados pelo PET-Saúde e pela influência desses efeitos sob a perspectiva de formação de novos profissionais efetivamente preocupados com a Atenção Primária à Saúde.

Salienta-se a importância de multiplicar e divulgar tais experiências para o fortalecimento da interação entre as diversas categorias profissionais, a articulação das açôes para promoção da saúde, o aprimoramento da formação profissional e a consolidação do SUS, através do conhecimento interdisciplinar (REGINA, 2010).

\section{Referências}

AGUIAR, S. R.; NERY, E.; PEIXOTO, M. T. PET-saúde da família, uma experiência interdisciplinar no cenário de prática das unidades de saúde da família - Feira de Santana-BA. In: SEMINÁRIO DE INICIAÇÃO CIENTÍFICA DA UNIVERSIDADE ESTADUAL DE FEIRA DE SANTANA, 14, Feira de Santana, 18 a 22 de outubro de 2010. Anais...

ALVES, V. S. Um modelo de educação em saúde para o Programa de Saúde da família: pela integralidade da atenção e reorientação do modelo assistencial. Interface, Botucatu, v. 9, n.16, p. 39-52, jul./ set. 2009.

BRASIL. Ministério da Educação. PET - Programa de Educação Tutorial: estratégia para o desenvolvimento da graduação. Brasília: Ministério da Educação, 2007. 150 p.

Ministério da Saúde e Ministério da Educação. Portaria Interministerial n. 1.802, de 26 de agosto de 2008. Brasília, DF: Ministério da Saúde, 2008. Disponível em: <http://bvsms.saude. gov.br/bvs/saudelegis/gm/2008/pri1802_26_08_2008.html>. Acesso em: 01 dez. 2012.

PEREIRA, I. B. A educação dos trabalhadores da saúde sob a égide da produtividade. In: MATTA, G. C.; LIMA, J. C. F. (orgs.)
Estado, sociedade e formação profissional em saúde: contradições e desafios em 20 anos de SUS. Editora FIOCRUZ /EPSJV. Rio de Janeiro, 2008. p. 393-420.

PEREIRA, T. F. Fundamentos da educação tutorial. In: BRASIL. Ministério da Educação. PET - Programa de Educação Tutorial: estratégia para o desenvolvimento da graduação. Brasília: Ministério da Educação, 2007. p. 135 - 139.

PINTO, M. E. B et al. Experiência interdisciplinar em equipe multiprofissional na graduação na atenção primária a saúde, PET-saúde UFCSPA. In.: CONGRESSO MULTIDISCIPLINAR DE SAÚDE COMUNITÁRIA DO MERCOSUL, 4., 2009, Gramado. Anais... Gramado: Universidade Federal de Ciências da Saúde de Porto Alegre, 2009.

REGINA, B.; VALLADÃO, F. O Programa de Educação pelo Trabalho para a Saúde fortalecendo a interdisciplinaridade na formação dos profissionais da área da saúde. Revista Ciência \& Saúde, Porto Alegre, v. 3, n. 1, p. 1, jan./jun. 2010

Recebido para publicação em Março/2012

Versão definitiva em Novembro/2012

Suporte financeiro: não houve

Conflito de interesse: inexistente 